are also being organised both by the Hunterian Society and by St George's Hospital.

John Hunter's work is enshrined today in the Hunterian Museum at the Royal College of Surgeons. He would be glad to know that his early researches are still the topics of continued interest among today's surgical scientists.

${ }^{1}$ Qvist, G, Annals of the Royal College of Surgery, 1977, 59, 205.

\section{Serum bile acids in hepatobiliary disease}

Can measuring the concentration of serum bile acids add anything useful to the information from other liver function tests? In 1939 Josephson $^{1}$ lamented that, though bile acid concentration in blood had been the subject of intensive investigation, the results from different analytic methods failed to agree and the scatter of values in liver disease was so great that the estimation was of no clinical use. Modern methods of measuring serum bile acids, however, are sensitive, precise, and in good agreement, and the time has come for a reappraisal.

Total serum bile acid concentration may be measured conveniently by a $3 x$-hydroxysteroid dehydrogenase assay, ${ }^{2}$ and gas-liquid chromatography allows individual bile acids to be distinguished. ${ }^{3}{ }^{4}$ Radioimmunoassay has added greatly to the sensitivity of bile acid estimation, and assays for the conjugates of cholic, chenodeoxycholic, and deoxycholic acids have been described, ${ }^{5}$ making serum bile acid measurement a practical clinical proposition.

The concentration of total serum bile acids indicates the fraction reabsorbed from the intestine that has escaped extraction on its first passage through the liver. These new techniques have established that measuring bile acids is a valid test of liver function, ${ }^{7-9}$ at least as sensitive as estimating $\gamma$-glutamyltranspeptidase concentrations, ${ }^{10}{ }^{11}$ and more specific for hepatobiliary disease. Some, ${ }^{912}$ but not all, ${ }^{10}$ reports have suggested that the serum bile acid concentration two hours after a meal is an even more sensitive indicator of liver dysfunction than are fasting concentrations. In spite of initial hopes, ${ }^{13}$ the disappearance rate of intravenously injected bile acid does not ${ }^{11}$ improve the sensitivity of the test, probably because in these circumstances clearance is more influenced by liver blood flow.

Recently Pennington et $a l^{10}$ showed that useful information about the type of liver disease may be obtained by measuring the individual bile acids by gas-liquid chromatography. The cholic:chenodeoxycholic acid ratio showed a clear distinction between patients with cirrhosis and with extrahepatic obstruc- w tion. The complete separation of the two groups reflects both $\frac{3}{2}$ the impairment of cholic acid synthesis in cirrhosis (probably $\stackrel{\mathbb{Q}}{\complement}$ due to damage to the $12 x$-hydroxylating mechanism) and a relative increase in cholic acid production in biliary obstruction. Patients with intrahepatic and extrahepatic cholestasis were $\overrightarrow{0}$ not compared, however, and the authors admitted that the $\frac{\bar{\partial}}{\bar{F}}$ cholic:chenodeoxycholic ratio would probably prove un- $\overline{\frac{\omega}{}}$ helpful here. A reduction in the glycine:taurine ratio of $\stackrel{\mathbb{Q}}{\circ}$ conjugated bile acids also occurs in liver disease, but is too variable to be diagnostically useful. ${ }^{14}$

The sceptic will want to know why another sensitive liver function test is needed at all, particularly when some existing $\vec{\omega}$ ones, such as the bromsulphthalein retention test, are rarely used. In chronic hepatitis, however, there is a real need for a non-invasive method of assessing disease activity and moni- $\vec{\sigma}$ toring treatment, and in a recent study from the Mayo Clinic $\overrightarrow{\vec{O}}$ determining the serum bile acids was much more useful for $\vec{\omega}$ these than conventional liver function tests. ${ }^{7}$ This important $\mathrm{N}$ work needs confirmation. Furthermore, some authors ${ }^{15}$ con- $\frac{\text { o }}{2}$ sider that normal serum bile acid concentrations must be $\vec{\infty}$ present for the diagnosis of Gilbert's syndrome (constitutional hyperbilirubinaemia).

Methods exist, then, for accurate measurement of total and individual serum bile acids, and with radioimmunoassay this could become a routine procedure. The place of these assays $\vec{\theta}$ in day-to-day clinical practice needs to be defined more $\varphi^{\circ}$ precisely, but at present they seem unlikely to supplant existing liver function tests. ${ }^{16}$

${ }^{1}$ Josephson, B, Fournal of Clinical Investigation, 1939, 18, 343.

2 Murphy, G M, Billing, B H, and Baron, D N, Fournal of Clinical Pathology, 1970, 23, 594.

3 Sandberg, D H, et al, fournal of Lipid Research, 1965, 6, 182.

${ }^{4}$ Ross, P E, Pennington, C R, and Bouchier, I A D, Analytical Biochemistry, $1977,80,458$.

5 Simmonds, W J, et al, Gastroenterology, 1973, 65, 705.

6 Demers, L M, and Hepner, G, Clinical Chemistry, 1976, 22, 602.

7 Korman, M G, Hofmann, A F, and Summerskill, W H J, New England Fournal of Medicine, 1974, 290, 1399.

${ }^{8}$ Fausa, O, and Gjone, E, Scandinavian fournal of Gastroenterology, 1976, 11, 537.

${ }^{9}$ Barnes, S, et al, fournal of Clinical Pathology, 1975, 28, 506.

10 Pennington, C R, Ross, P E, and Bouchier, I A D, Gut, 1977, 18, 903.

${ }^{11}$ Thjodleifsson, B, et al, Gut, 1977, 18, 697 .
${ }^{2}$ Kaplowitz, N, and Javitt, B, fournal of the American Medical Association, 1973, 225, 292.

${ }^{13}$ LaRusso, N F, et al, New England fournal of Medicine, 1975, 292, 1209.

${ }^{14}$ Neale, G, et al, Gut, 1971, 12, 145.

15 Javitt, N B, Clinics in Gastroenterology, 1977, 6 (i), 219.

16 British Medical fournal, 1977, 2, 75. 